\title{
A rare case of acute alcohol intoxication mimicking an electrocardiographic pattern for acute coronary syndrome with ST-segment elevation
}

\author{
Franco Lai, ${ }^{1}$ Lorenzo Pelagatti, ${ }^{1}$ Chiara Pagnini, ${ }^{2}$ Alessio Baldini, ${ }^{1}$ Daniele Versari, ${ }^{1}$ \\ Simone Magazzini ${ }^{1}$ \\ ${ }^{1}$ Emergency Department, Santo Stefano Hospital, Prato; ${ }^{2}$ School of Medicine, University of Florence, \\ Florence, Italy
}

\begin{abstract}
A patient presenting an ST-segment elevation could represent a life-threatening condition in Emergency Department (ED). This case shows how sometimes, a chronic, and more often, an acute abuse of alcohol is related to important harmful effects on myocardial contractility. The authors present a case of a 19-year-old male of oriental-Asiatic origin admitted unconscious to ED with alcoholic fetor: on electrocardiogram a significant and widespread STsegment elevation was observed. A bedside echocardiography showed no abnormalities in segmental kinetics; therefore electrocardiogram-alterations could be related to a coronary spasm. The literature is poor about this effect induced by acute alcohol ingestion: the pathophysiological mechanism at the base of the abnormal muscle contractility, seems to be related to an impairment in cyclic guanosine monophosphate production, although a second and less probable hypothesis could be an altered intracellular concentration of calcium levels.
\end{abstract}

\footnotetext{
Correspondence: Franco Lai, Emergency Department, Santo Stefano Hospital, via San Paolo 271, 59100, Prato, Italy.

E-mail: franco.lai@uslcentro.toscana.it

Key words: Acute alcohol intoxication; ST-segment elevation; coronary vasospasm.

Contributions: FL, DV, patient's treatment and manuscript writing; LP, $\mathrm{CP}$, literature research and manuscript revising; $\mathrm{AB}, \mathrm{SM}$, case report supervising.

Conflict of interest: the authors declare no potential conflict of interests.

Ethics approval and consent to participate: The manuscript does not contain any elements that would allow the recognition of the patient.

Informed consent: informed consent was obtained from the patient.

Received for publication: 1 October 2019.

Revision received: 15 November 2019.

Accepted for publication: 20 December 2019.

This work is licensed under a Creative Commons Attribution 4.0 License (by-nc 4.0).

(Copyright: the Author(s), 2020

Licensee PAGEPress, Italy

Emergency Care Journal 2020; 16:8596

doi:10.4081/ecj.2020.8596
}

\section{Case Report}

The authors present a case of a 19-year-old male of orientalAsiatic origin who was admitted unconscious to the Emergency Department presenting a Glasgow coma scale (GCS) 3 with alcoholic fetor. The patient showed a normal physical examination and no recent trauma signs were observed. A correct AMPLE evaluation was impossible at the admission due to the absence of witnesses. Ancillary blood tests were performed: plasma glucose, hemocromocytometric sample, renal and hepatic tests, electrolytes [white blood cells count $7.4 \times 10^{3} / \mu \mathrm{L}$, red blood cells count $5.21 \times 10^{6} / \mu \mathrm{L}$, hemoglobin $(\mathrm{Hb}) 15.2 \mathrm{~g} / \mathrm{dL}$, hematocrit $44.3 \%$, blood urea nitrogen $25 \mathrm{mg} / \mathrm{dL}$, glucose:129 mg/dL, $\mathrm{Na}^{+} 141$ $\mathrm{mEq} / \mathrm{L}, \mathrm{K}^{+} 3.1 \mathrm{mEq} / \mathrm{L}, \mathrm{Cl}^{-} 104 \mathrm{mEq} / \mathrm{L}$, aspartate transaminase 21 $\mathrm{UI} / \mathrm{L}$, alanine transaminase $26 \mathrm{UI} / \mathrm{L}$, creatine kinase $120 \mathrm{UI} / \mathrm{L}$, lactate dehydrogenase $158 \mathrm{UI}$, pancreatic amylase $30 \mathrm{UI} / \mathrm{L}$, bilirubin $0.7 \mathrm{mg} / \mathrm{dL}$, fibrinogen $302 \mathrm{mg} / \mathrm{dL}$, international normalized ratio 1], and acid-base balance $\left(\mathrm{pH} 7.36, \mathrm{pCO}_{2} 40.0 \mathrm{mmHg}, \mathrm{pO}_{2} 100\right.$ mmHg, $\mathrm{Hb} 14.9$ g/dL, $\mathrm{SpO}_{2}$ 97.5\%, Glu: $129 \mathrm{mg} / \mathrm{dL}, \mathrm{HCO}_{3}{ }^{-} 22.2$ $\mathrm{mmol} / \mathrm{L}$ ). A toxicological panel for plasma and urines was performed as well, and resulted normal except for alcohol concentration. Serum lactate was $2.1 \mathrm{mmol} / \mathrm{L}$. Blood pressure was $105 / 50$ $\mathrm{mmHg}$, heart rate $68 \mathrm{bpm}$; tympanic temperature was $36.2^{\circ} \mathrm{C}$.

The initial treatment was addressed to airway protection with orotracheal intubation (induction with propofol and rocuronium) and the patient was ventilated with $100 \%$ oxygen; after that, gastric aspiration was performed with no result as the stomach was empty. The pharmacological treatment consisted in coma cocktail drugs (naloxone $0.4 \mathrm{mg}$, flumazenil $0.1 \mathrm{mg} / 5 \mathrm{~mL}$, D5W $250 \mathrm{~mL}$, normal saline and thiamine). A head computed tomography (CT) scan showed normal patterns.

Moreover, an electrocardiogram was performed and surprisingly showed a significant and widespread ST-segment elevation (Figure 1); the blood tests revealed a high blood alcohol level $(3.6 \mathrm{~g} / \mathrm{L})$ with a normal I isoform troponin level $0.01 \mathrm{ng} / \mathrm{mL}$ (normal value: 0.00 $0.06 \mathrm{ng} / \mathrm{mL}$ ). The cardiologist consultant performed a bedside echocardiography which showed no abnormality of heart segmental kinetics, and subsequently, $12 \mathrm{~h}$ after pharmacological treatment, the patient gained consciousness and was extubated. He showed sudden normalization of the electrocardiogram (ECG) (Figure 2) associated with normal ethanol blood level (0.18 g/L) $15 \mathrm{~h}$ after admission. Therefore, the authors hypothized that an alcohol-related coronary spasm could be the cause of the ECG-alterations.

\section{Discussion}

Chronic and acute alcohol abuse are causes of important side effects on myocardial function and perfusion. Chronic alcohol intake induces cardiomyopathy, cardiac rhythm disorders and sud- 
den death. ${ }^{1-3}$ The literature on ST-segment elevation in acute alcohol intoxication in humans is poor, although we know that in experimental animal acute alcohol intoxication can induce alterations in the ST segment. Literature in humans remains poor.

Chronic alcohol intake represents a well-known risk factor for cardiovascular disease. The acute form of alcohol intoxication is associated with several clinical manifestations including cardiovascular function, such as important reduction on left ventricle contractility, which appears more severe in patients affected by coronary artery disease. ${ }^{4}$

Ethanol acts in chronic inducing myocardial damage, linked to: i) direct toxic effects: uncoupling of the excitation-contraction system; reduced calcium sequestration in the sarcoplasmic reticulum; membrane inhibition of $\mathrm{Na}+\mathrm{K}+\mathrm{ATP}$-dependent pump; respiratory alterations of the myocytes; increased synthesis of the extracellular matrix; ii) toxic effects of metabolites: acetaldehyde and ethyl esters; iii) nutritional deficiency and deficiencies of trace elements: thiamine and selenium; iv) electrolyte imbalances: hypomagnesemia, hypokalemia, hypophosphatemia; v) toxic additives: lead and cobalt. ${ }^{5-8}$

Chronic alcohol abuse is associated with coronary artery disease, arrhythmias and sudden cardiac death. Levels of triglycerides and very low-density lipoprotein (LDL) are increased in these patients; the chronic intake of conspicuous doses is also associated with an increase in LDL cholesterol and a decrease in high-density lipoprotein: these alterations are the basis of an increased coronary risk. Alcohol abusers are also more likely to experience high blood pressure and increased left ventricular muscle mass (diastolic or systolic dysfunction).

Those who chronically intake high quantities of alcohol have a higher incidence of arrhythmias, including: supraventricular or ventricular ectopic beats, supraventricular tachycardia, atrial flutter, atrial fibrillation (the most frequent), ventricular tachycardia and ventricular fibrillation. ${ }^{8,9}$

One of the most important clinical pictures in acute alcohol intoxication is represented by the so called Holiday Heart Syndrome. The syndrome described in 1978 shows a frequent onset of paroxysmal supraventricular arrhythmias, such as atrial fibrillation, and symptoms usually disappear within $24 \mathrm{~h} .{ }^{10,11}$

In experimental animal models induced to acute alcohol intoxication, ischemia/reperfusion heart susceptibility resulted increased and the normal left ventricular contractility became physiologic within 6 hours after alcohol peak. ${ }^{12}$ Ethanol treated rats showed indeed an elevated ST-segment after $24 \mathrm{~h}$ and a long $\mathrm{QT}_{\mathrm{c}}$ after 6 and $24 \mathrm{~h}$ as compared to the control group. ${ }^{12,13}$

Aldehyde dehydrogenase $2^{9}$ variant $2(\mathrm{ALDH} 2 * 2)$ is considered a harmful risk factor for coronary spasm and myocardial infarction with ST elevation.

Minzuno et al. ${ }^{9}$ demonstrated that ALDH2*2 is involved in ethylic alcohol detoxification in acute myocardial infarction with ST-elevation $(51.0 \%)$ and this group of patients showed more severe myocardial lesions than other enzyme isoform of aldehydedehydrogenase. Similarly, Xu et al. ${ }^{14}$ demonstrated that Glu504lys polymorphism for ALDH2* is related to major cardiovascular events such as acute coronary syndromes and sudden cardiac death.

The chronic effects of ethanol on cardiovascular system are well-known; on the other hand, the acute effects are not completely understood. Ethanol has a psychoactive effect when ingested at high doses and provides a documented action on cardiovascular system: in addition to skin vasodilation responsible for the sensation of heat and redness, ethanol is able to produce coronary vasospasm. Ando et al. ${ }^{15}$ have described the potential role of acetaldehyde level (a metabolite produced by the action of alcohol dehydrogenase) in myocardial ischemia: in this article the authors present a patient with angina who suffered ischemia related with alcohol ingestion and abnormal high level of acetaldehyde. In vitro a study by Altura et al. ${ }^{16}$ has analyzed the effects of ethanol and acetaldehyde on medium and small caliber coronary vessels: the authors noted that the exposure to $8.5 \mathrm{Mm}$ of alcohol can induce the contraction of the cardiac arteries; conversely the acetaldehyde has instead a relaxing action on vascular basal tone. Altura et al. have therefore correlated this effect on the vascular system to the depression of cardiac contractility, arrhythmias, cardiomyopathy and increased incidence of sudden cardiac death observed in patients with a history of alcohol abuse. The authors failed to identify the underlying pathophysiological mechanism: they did not find the involvement of the adrenergic system, histamine or 5-HT, so they hypothesized that this effect could be caused by a paracrine and autocrine action of the endothelium. Consistently with literature, we speculated that alcohol levels might be correlated to myocardial ischemia since ECG pattern normalization only occurred with alcohol level normalization.

Electrolytes imbalance has been hypothesized in acute alcohol induced angina: Miwa et al..$^{17}$ have studied the role of magnesium $(\mathrm{Mg})$ imbalance in alcohol induced variant angina based on studies that suggest an involvement of $\mathrm{Mg}$ deficiency as trigger of the coronary spasm. The authors have supposed that increased urinary $\mathrm{Mg}$ excretion induced by alcohol assumption may be the cause of acute alcohol induced angina. The $\mathrm{Mg}$ normal concentration is 1.7$2.2 \mathrm{mg} / \mathrm{dL}(1.4-1.8 \mathrm{mEq}$ and $0.7-0.9 \mathrm{mmol} / \mathrm{L})$ : in our case the blood sample shows a value in range but at the lower limit (1.7 $\mathrm{mg} / \mathrm{dL}$ ). Probably this is not the mechanism involved in our report because as Miwa et al. suggest chronic alcohol intake could be a

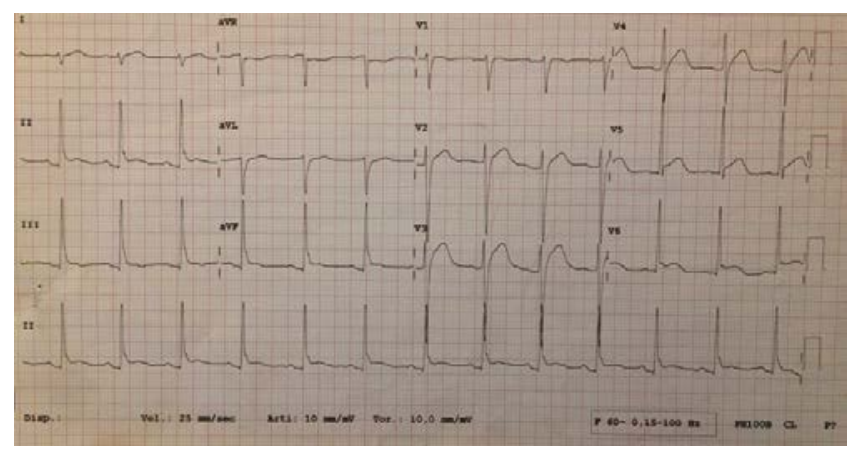

Figure 1. Emergency Department admission.

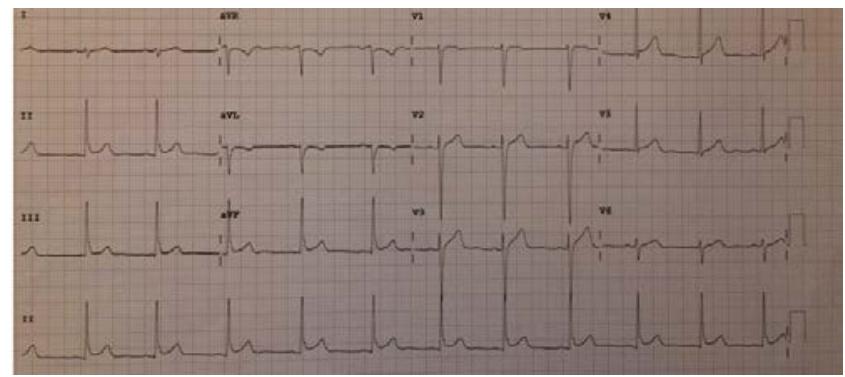

Figure 2. $12 \mathrm{~h}$ later after Emergency Department admission. 
risk factor for coronary artery spasm through $\mathrm{Mg}$ deficiency, while in our case the effect was due to acute ingestion and the patient would probably not have had the time to develop hypomagnesemia.

Puddey et al. ${ }^{18}$ in addition to the known effects related to the ingestion of high amounts of alcohol (increased risk of coronary heart disease and ischemic and hemorrhagic stroke) have found in vitro that while low amounts of alcohol determine an increase in nitric oxide (NO) and therefore an increase in endothelium-mediated vasodilation, an ingestion of high doses of alcohol in acute leads to an impairment in vascular relaxation. Similarly, Brizzolara et al. ${ }^{19}$ found that alcohol at high concentrations causes a decrease in maximum relaxation and sensitivity of the vessels to acetylcholine. During in vitro experiments conducted by Hatake et al. ${ }^{20}$ endothelium-dependent relaxation was consistently decreased by exposure of the vessels to alcohol.

The coronary vasospasm is considered a non-specific contractile response of vascular smooth muscle in response to the stimulation by various agonists or in response to an inflammatory process which can induce fibrocellular proliferation. $\mathrm{Ca}^{++}$interaction with calmodulin-activated myosin light chain (MLC) kinase with subsequent phosphorylation of MLC $^{21}$ is necessary for vascular smooth muscle contraction. Yasue et al. ${ }^{21}$ described as coronary arterial hypercontractility is related to: i) an increased intracellular flow of $\mathrm{Ca}^{++}$that leads to an increase level of free intracellular $\mathrm{Ca}^{++}$; ii) an hypersensitivity to $\mathrm{Ca}^{++}$of the contractile proteins of vascular smooth muscle cells.

Oda et al. ${ }^{22}$ in an old 1994 study, when the pathophysiological mechanism that carried coronary vasospasm was unknown, studied 8 patients who had documented a relationship between alcohol ingestion and episodes of chest pain with elevation of the ST segment. The pain in these patients was treated with sublingual nitroglycerin as soon as it appeared: nitroglycerin provided the complete resolution of symptoms. An angiography was performed in 4 patients presenting with pain and alteration of the ST segment: in 3 cases there were alterations of ventricular activation time or intravenous pyleogram, which reflected what was observed on ECG. Oda et al. in these patients measured blood levels of: ethanol, serotonin, catecholamines, prostanoids, cyclic nucleotides (cGMP, cAMP), platelet aggregability. The results of those patients to whom alcohol had been given and who had angina were then compared to healthy controls: normal values were found for all the analyzed items in patients with chest pain except for cGMP, whose levels were extremely low. ${ }^{2}$

It is difficult to demonstrate the role that may have $\mathrm{NO}$, calcium sensitivity and alteration in messenger synthesis (cGMP): however, it is likely to assume that the sum of these factors could have an addictive role in the dysregulation of vascular tone. Summing up what emerges from literature it is possible to hypothesize that at the base of the alterations of the ST segment there is an alteration of coronary contractility: vasospasm is the cause of the electrocardiographic alterations. ${ }^{2,23}$ The vascular tone is increased because there is an impairment in the function of the NOS with a decrease level of NO, and consequently with a decrease in cGMP, an important second messenger implicated in coronary vasodilation: this creates an imbalance between the mediators that cause contraction and those that release the vascular smooth muscle. Another possible mechanism is linked to a calcium-mediated hypercontractivity. These mechanisms then act on an underlying genetic substrate of the patient: the level of alcohol dehydrogenase activity influences the rate of ethanol metabolism, therefore the patients with low enzyme activity will be more exposed to episodes of vasospasm. ${ }^{5,23}$

\section{Conclusions}

Electrocardiographic and vascular abnormalities due to high doses of alcohol are rare, however they can be one of the causes of ST segment alteration which leads physicians to investigate an acute coronary syndrome. It is important to keep in mind this effect in patients who abuse large quantities of alcohol and who arrive in ED with altered GCS and ST segment elevation.

\section{References}

1. Takehana H, Izumi T. [Alcoholic heart disease]. Nihon Rinsho 2000;58:151-6. [Article in Japanese].

2. Brawnwald E, ed. Heart disease: a textbook of cardiovascular medicine. 5th edition. Philadelphia, PA: W.B. Saunders Company; 1997. pp 1412-1414.

3. Suzuki K, Osada N, Akasi YJ, et al. An atypical case of "Takotsubo cardiomyopathy" during alcohol withdrawal: abnormality in the transient left ventricular wall motion and a remarkable elevation in the ST segment. Intern Med 2004; $43: 300-5$.

4. Ahmed SS, Levinson GE, Regan TJ. Depression of myocardial contractility with low doses of ethanol in normal man. Circulation 1973;48:378-85.

5. Ahmed SS, Levinson GE, Regan TJ. Depression of myocardial contractility with low doses of ethanol in normal man. Circulation 1973;48:378-85.

6. Maguire R. Acute dilatation of the heart produced by alcoholism. Br Med J 1887;1:1215.

7. Niccoli G, Altamura L, Fabretti A, et al. Ethanol abolishes ischemic preconditioning in humans. J Am Coll Cardiol 2008;51:271-5.

8. Feng Xu, Chen YG, Li Xue, et al. Role of aldehyde dehydrogenase 2 Glu504lys polymorphism in acute coronary syndrome. J Cell Mol Med 2011;15:1955-62.

9. Mizuno Y, Hokimoto S, Harada E, et al. Variant aldehyde dehydrogenase $2(\mathrm{ALDH} 2 * 2)$ is a risk factor for coronary spasm and ST-segment elevation myocardial infarction. J Am Heart Assoc 2016;5:5.

10. Maguire R. Acute dilatation of the heart produced by alcoholism. Br Med J 1887;1:1215.

11. Ettinger PO, Wu CF, De la Cruz C, et al. Arrhythmias and the holiday heart: alcohol-associated cardiac rhythm disorders. Am. Heart J 1995;5:555-62.

12. Niccoli G, Altamura L, Fabretti A, et al. Ethanol abolishes ischemic preconditioning in humans. J Am Coll Cardiol 2008;51:271-5.

13. Correale M, Laonigro I, Altomare E, Di Biase M. [Alcoholinduced cardiac disease]. G Ital Cardiol (Rome) 2009;10:1827. [In Italian].

14. Feng X, Chen YG, Li X, et al. Role of aldehyde dehydrogenase 2 Glu504lys polymorphism in acute coronary syndrome. J Cell Mol Med 2011;15:1955-62.

15. Ando H, Abe H, Hisanou R. Ethanol-induced myocardial ischemia: close relation between blood acetaldehyde level and myocardial ischemia. Clin Cardiol 1993;16:443-6.

16. Altura BM, Altura BT, Carella A. Ethanol produces coronary vasospasm: evidence for a direct action of ethanol on vascular muscle. Br J Pharmacol 1983;78:260-2.

17. Miwa K, Igawa A, Miyagi Y. Importance of magnesium deficiency in alcohol-induced variant angina. Am J Cardiol 
1994;73:813-6.

18. Puddey IB, Zilkens RR, Croft KD, Beilin LJ. Alcohol and endothelial function: a brief review. Clin Exp Pharmacol Physiol 2001;28:1020-4.

19. Brizzolara AL, Morris DG, Burnstock G. Alcohol affects sympathetic cotransmission and endothelium-dependent relaxation in the rat. Eur J Pharmacol 1994;254:175-81.

20. Hatake K, Wakabayashi I, Kakishita E, et al. Inhibitory effect of alcohol on endothelium-dependent vascular responsiveness. Eur J Pharmacol 1989;168:277-83.

21. Yasue H, Kugiyama K. Coronary artery spasm. Clinical fea- tures, pathogenesis and treatment. In: Yasue H, ed. Coronary artery spasm. Berlin-Heidelberg-New York-Tokyo; Springer; 2000. pp 9- 18.

22. Oda H, Suzuki M, Oniki T, et al. Alcohol and coronary spasm. Angiology 1994;45:187-97.

23. Suzuki K, Osada N, Akasi YJ, et al. An atypical case of "Takotsubo cardiomyopathy" during alcohol withdrawal: abnormality in the transient left ventricular wall motion and a remarkable elevation in the ST segment. Intern Med 2004;43:300-5. 